\title{
Protein Phosphatase-1 Inhibitor-2 Is a Novel Memory Suppressor
}

\author{
Hongtian Yang, ${ }^{1}$ Hailong Hou, ${ }^{1 \star}$ Amanda Pahng, ${ }^{3 \star}$ Hua Gu, ${ }^{1}$ Angus C. Nairn, ${ }^{5}$ Ya-Ping Tang, ${ }^{2}$ Paul J. Colombo, ${ }^{4}$ \\ and Houhui Xia ${ }^{1,2}$ \\ ${ }^{1}$ Neuroscience Center of Excellence, School of Medicine, and ${ }^{2}$ Department of Cell Biology and Anatomy, Louisiana State University Health Science Center, \\ New Orleans, Louisiana 70112, ${ }^{3}$ Neuroscience Program and ${ }^{4}$ Department of Psychology, Tulane University, New Orleans, Louisiana 70118, and \\ ${ }^{5}$ Department of Psychiatry, Yale University, New Haven, Connecticut 06511
}

Reversible phosphorylation, a fundamental regulatory mechanism required for many biological processes including memory formation, is coordinated by the opposing actions of protein kinases and phosphatases. Type I protein phosphatase (PP1), in particular, has been shown to constrain learning and memory formation. However, how PP1 might be regulated in memory is still not clear. Our previous work has elucidated that PP1 inhibitor-2 (I-2) is an endogenous regulator of PP1 in hippocampal and cortical neurons (Hou et al., 2013). Contrary to expectation, our studies of contextual fear conditioning and novel object recognition in I-2 heterozygous mice suggest that I- 2 is a memory suppressor. In addition, lentiviral knock-down of I-2 in the rat dorsal hippocampus facilitated memory for tasks dependent on the hippocampus. Our data indicate that I-2 suppresses memory formation, probably via negatively regulating the phosphorylation of cAMP/calcium response element-binding protein (CREB) at serine 133 and CREB-mediated gene expression in dorsal hippocampus. Surprisingly, the data from both biochemical and behavioral studies suggest that I-2, despite its assumed action as a PP1 inhibitor, is a positive regulator of PP1 function in memory formation.

Key words: CREB; inhibitor 2; knock-out; memory; Protein phosphatase 1; RNAi

\section{Significance Statement}

We found that inhibitor-2 acts as a memory suppressor through its positive functional influence on type I protein phosphatase (PP1), likely resulting in negative regulation of cAMP/calcium response element-binding protein (CREB) and CREB-activated gene expression. Our studies thus provide an interesting example of a molecule with an in vivo function that is opposite to its in vitro function. PP1 plays critical roles in many essential physiological functions such as cell mitosis and glucose metabolism in addition to its known role in memory formation. PP1 pharmacological inhibitors would thus not be able to serve as good therapeutic reagents because of its many targets. However, identification of PP1 inhibitor-2 as a critical contributor to suppression of memory formation by PP1 may provide a novel therapeutic target for memory-related diseases.

\section{Introduction}

Memory formation is known to be coordinated by the opposing actions of many protein kinases and phosphatases. Type I protein phosphatase (PP1), in particular, has been shown to constrain learning and memory formation (Genoux et al., 2002). CREB (cAMP/calcium response

\footnotetext{
Received May 14, 2015; revised 0ct. 3, 2015; accepted 0ct. 8, 2015.

Author contributions: Y.-P.T., P.J.C., and H.X. designed research; H.Y., H.H., A.P., and H.G. performed research; H.Y., H.H., A.P., Y.-P.T., P.J.C., and H.X. analyzed data; A.C.N., P.J.C., and H.X. wrote the paper.

This work was supported by the National Institutes of Health (Grant R01NS060879 to H.X. and Grant DA10044 to A.C.N.), the National Science Foundation (Grant IOS-1457336 to H.X. and Grant IOS-0849800 to P.J.C.), and the Louisiana State University Research Enhancement Fund (H.X.).

The authors declare no competing financial interests.

*H.H. and A.P. contributed equally to this work.

Correspondence should be addressed to Dr. Houhui Xia, Neuroscience Center of Excellence, School of Medicine, LSUHSC, New Orleans, LA 70112. E-mail: hxia@|suhsc.edu.

DOI:10.1523/JNEUROSCI.1865-15.2015

Copyright $\odot 2015$ the authors $\quad 0270-6474 / 15 / 3515082-06 \$ 15.00 / 0$
}

element-binding protein) is one of the well known memory substrates that are regulated by reversible phosphorylation. Control of CREBmediated gene expression via CREB phosphorylation at serine 133 (pCREB) is critical for late-phase synaptic plasticity (Barco et al., 2002) and memory formation (Shaywitz and Greenberg, 1999; Lonze and Ginty, 2002; Impey et al., 2004). PP1 is a major CREB phosphatase at serine 133 and was found to constrain memory formation (most likely via inactivating CREB) in a transgenic mouse model (Genoux et al., 2002). Inhibiting PP1 activity has been shown to increase phosphorylation of CREB (Alberts et al., 1994; Bito et al., 1996) and to enhance memory (Genoux et al., 2002). However, how PP1 is regulated in CREB-mediated gene expression and memory formation is not clear.

Inhibitor-2 (I-2) is the prototypic inhibitor of PP1. Before the DNA sequencing era, I-2, along with inhibitor-1 (I-1), was used in in vitro assays to distinguish, and thus define, PP1 from other families of serine/ threonine protein phosphatases (Cohen, 1989). I-2 inhibition of PP1 has been studied extensively in in vitro for decades since its purification 
in 1976; however, the lack of I-2 knock-out (KO) mice, attributed by some to the existence of many I-2 pseudogenes, has led to scarce knowledge of I-2's function in vivo.

We and others have found that I-2 is expressed at high levels in hippocampal and cortical neurons (Sakagami and Kondo, 1995; Siddoway et al., 2013) and that I-2 is essential for chemical LTD in primary neurons (Hou et al., 2013). Moreover, we found that I-2 knock-down, but not I-1 knock-down, in primary cortical neurons leads to decreased PP1 activity based on increased PP1 inhibitory phosphorylation at Thr320 (Hou et al., 2013), suggesting that I-2 may have a more complex function than simply acting to inhibit PP1 in cortex and hippocampus, brain regions playing critical roles in memory formation.

In this study, we made I-2 gene-trapping mutant mice to study I-2's potential role in memory formation. Even though global I-2 $\mathrm{KO}$ mice die as embryos, I-2 heterozygous mice $\left(\mathrm{I}-2^{+-}\right)$are viable, fertile, and have no obvious phenotypes. Interestingly, $\mathrm{I}-2^{+/-}$mice exhibit increased memory formation in both novel object recognition and contextual fear conditioning (CFC) tests. This function of I-2 to regulate memory formation negatively was further demonstrated by infusion of I-2 shRNA-encoding lentivirus into the dorsal hippocampus of adult rats, which enhanced spatial memory and CFC. Moreover, we found that PCREB levels were significantly enhanced in I-2 KD neurons in the dorsal hippocampus. In addition, we found increased mRNA levels of the CREB-regulated genes BDNF, c-fos, Homerla, and Egrl in I-2 KD neurons. These data suggest that I-2 is a positive regulator of PP1, acting to negatively regulate CREB activation and CREB-mediated gene expression. Our study has thus identified I-2 as a memory suppressor that can exert positive regulation of $\mathrm{PP} 1$ action in vivo.

\section{Materials and Methods}

\section{I-2 KO mice}

I-2 gene-trapping embryonic stem cells (ES, S129 background) were purchased from Lexicon Pharmaceuticals via the Texas Institute of General Medicine. I-2 heterozygous mice were made via blastocyst injection of I-2 gene-trapping ES cells and confirmed by PCR genotyping. I-2 homozygous mice die as embryos. I-2 heterozygous mice were bred with C57BL/6N mice for $>10$ generations before behavior tests on mixed male/female mice were performed.

\section{Behavioral tests of memory formation in mice}

All experimental protocols for live animals were approved by the Institutional Animal Care and Use Committees of the Louisiana State University Health Science Center and Tulane University.

Novel object recognition. We followed the protocol used by Tang et al. (1999) in their previous studies. In brief, mice were individually habituated for $3 \mathrm{~d}$ before training, during which two novel objects were placed in the apparatus and the individual mouse was allowed to explore for 5 min. During the memory retention test, the individual mouse was put back into the chamber and was allowed to explore freely for $5 \mathrm{~min}$. Exploration of an object was considered when the head of animal was facing and within 1 inch from, the object.

CFC. For CFC experiments, different sets of mice were individually habituated before training, during which mice were put individually into the chamber and allowed to explore freely for $2.5 \mathrm{~min}$. A foot shock of 0.8 $\mathrm{mA}$ was delivered for $2 \mathrm{~s}$ and the mouse was allowed to stay in the chamber for another $30 \mathrm{~s}$. Freezing was judged as complete immobility of the body except for respiratory movements. During the retention test, mice were individually placed in the shock chamber and freezing responses were recorded for $3 \mathrm{~min}$ in this context.

\section{Lentivirus injection and behavioral analysis in rats}

Surgical procedure. Stereotaxic surgery and injection coordinates were as described previously (Kathirvelu et al., 2013). Surgical shams underwent the same surgical procedures as the lentiviral-infused rats except nothing was infused into the dorsal hippocampus. All rats were given 2 weeks to recover from surgery before behavioral training began.

Spatial training. Two weeks after hippocampal infusion, rats began spatial training in a water maze. Spatial memory was assessed using a place task in which rats were pseudorandomly started from one of four start locations and trained to find a hidden platform in the water maze. Rats were given 3 trials of spatial training per day for a total of $4 \mathrm{~d}$. The trial ended when the rat reached the platform or when $90 \mathrm{~s}$ elapsed and the rat was led to the platform by the experimenter. Rats remained on the platform for $15 \mathrm{~s}$ and were placed in a carrying cage for $15 \mathrm{~s}$ in between trials. The sixth and $12^{\text {th }}$ trials (last trial of days 2 and 4 ) were probe trials to measure spatial bias during which the platform was retracted for the first $30 \mathrm{~s}$ of the probe trial.

CFC. For CFC, rats were trained as described previously (Kathirvelu et al., 2013; Kathirvelu and Colombo, 2013).

\section{Primary neuronal cell cultures}

Primary cortical neurons were prepared from mixed male/female E18 Sprague Dawley rat embryos (Siddoway et al., 2014).

\section{Total RNA isolation and quantitative PCR}

Total RNA was isolated and purified from cortical cultures using RNeasy kit (Qiagen). Total RNA was then reverse transcribed to cDNA with iScript cDNA synthesis kit (Bio-Rad). Real-time PCR was performed using a CFX Real-Time PCR detection system with iQ SYBR Green kit (Bio-Rad). The expression of the genes of interest was quantitated and normalized against GAPDH gene expression. The sequences for PCR primers were as follows (F: forward, R; reverses): F I-2: CCTGCTCTGATTTCCTAC, R I-2: CAGCAGATGACAGACTAC; F BDNF: GACAGTATTAGCGAGTGG, R BDNF: GGGATTACACTTGGTCTC; F c-fos: GACAGCCTTTCCTACTAC, R cfos: CACTAGAGACGGACAGAT; F Homer-1a: CAGGAGAAGATGGAACTG, R Homer-1a: GGGTGTTCTCTCATCATC; F Egr1: GAGTGATGAACGCAAGAG, R Egr1: GTAGGAAGAGAGGGAAGAG; F GAPDH: GTAGGAAGAGAGGGAAGAG, R GAPDH: GAAGTCACAGGAGACAAC.

\section{Western blotting}

Western blotting was performed as described previously (Kathirvelu et al., 2013; Hou et al., 2014). Mouse left brain hemispheres were dissected out from adult mice ( 2.5 months) and immediately flash frozen in liquid nitrogen. The frozen brain samples were subject to grinding and sonication in CelLytic MT Cell Lysis Reagent (Sigma-Aldrich, C3228). Protein concentrations were determined with the DC Protein Assay kit (Bio-Rad, 500-0114) to ensure equal loading by SDS-PAGE.

For immunoprecipitation (IP) and measurement of PP1 enzymatic activity from I-2 or control immunoprecipitates ( ${ }^{32} \mathrm{P}$ based), 3-week or older neurons were used for IP with I-2 antibody, PP1 antibody, or the corresponding control IgG (Hou et al., 2013). PP1 enzymatic assays were performed as described previously (Le et al., 2011). ${ }^{32}$ P-labeled histone (purified, Sigma-Aldrich) was used as PP1 substrate in the assay. In vitro kinase reaction of histone with purified PKA plus ATP was performed as described previously (Le et al., 2011). The amount of antibodies, including control IgGs, was further determined to be similar in each IP by Western blotting. PP1 activity in each IP was determined as the difference between that measured in the presence of okadaic acid $(1 \mu \mathrm{M}$, blocks PP1/PP2A) and microcystin (0.5 nM, blocks mainly PP2A) treatment before normalized over the amount of IP antibody.

\section{Statistical analysis}

Mouse behavioral test. Mice were used for only one round of training and retention session in both novel object and CFC test. $t$ test was used to compare wild-type and I-2 heterozygous mice at each retention time point.

Gene expression. qRT-PCR RNA levels of the I-2 knock-down sample were normalized against that of the control knock-down sample and expressed as the fold change. The fold change values of all genes were then compared with 1 (no change) using one-sample $t$ test.

Western blotting for mouse and primary culture studies. Proteins levels were normalized against $\beta$-tubulin or total CREB. $t$ tests were used for comparing two groups of samples. All the results are expressed as mean \pm SEM. For $t$ test, significance level was set at $p<0.05$. 
A

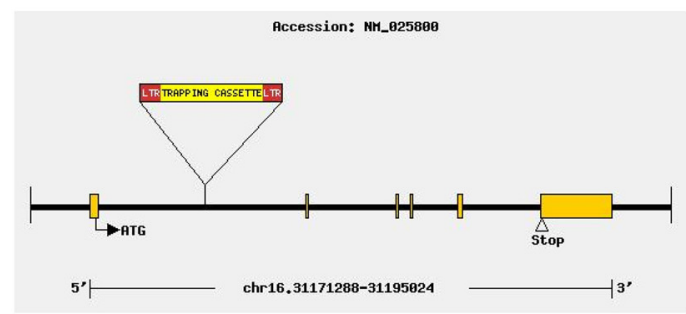

C

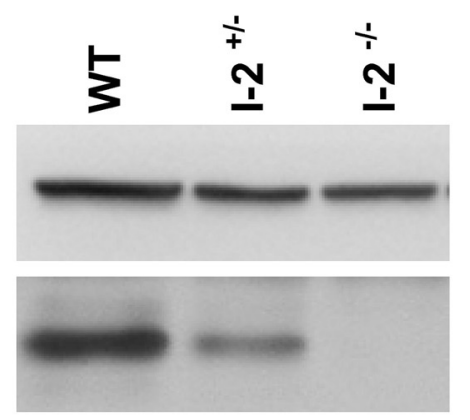

D

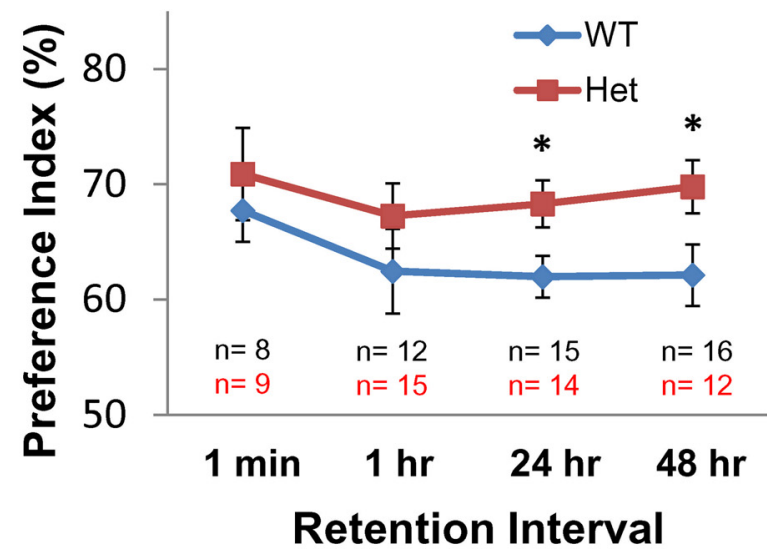

I-2
B
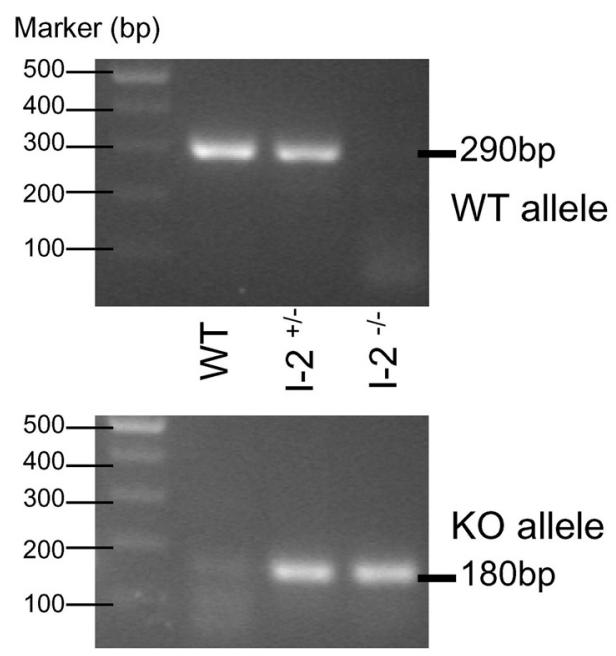

$\mathbf{E}$

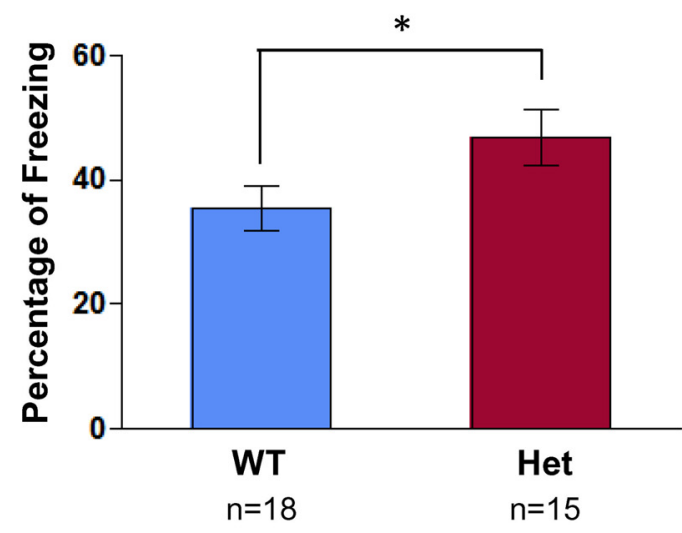

Figure 1. I-2 negatively regulates memory formation in mice. $\boldsymbol{A}$, Schematic of $\mathrm{I}-2$ gene trapping. A large DNA cassette was inserted in the first intron of the mouse I-2 gene. $\boldsymbol{B}$, Genotyping of I-2 mice. C, Western blotting confirmation of absence of $\mathrm{I}-2$ protein in $\mathrm{I}-2 \mathrm{KO}$ mice $(\mathrm{E} 10.5)\left(\mathrm{I}-2^{-1-}\right.$ mice die as embryos). $D, \mathrm{I}-2^{+/-}$mice $(>2.5$ months old) exhibit increased preference for a novel object compared with their wild-type littermates in a novel object recognition test 24 and $48 \mathrm{~h}$ after training. ${ }^{*} p<0.05,2$-tailed $t$ test. $E, I-2^{+/-}$mice exhibit increased freezing compared with their wild-type littermates in a CFC test. ${ }^{*} p<0.05,2$-tailed $t$ test.

All rat data were analyzed using SPSS software. For the spatial memory task, repeated-measures ANOVAs were used to analyze group differences in latency to find the platform across days, percent time in target quadrant across probes, and proximity to the platform across the probes. A posteriori comparisons were performed using Fisher's LSD test. One-way ANOVAs were used to analyze differences in freezing between groups for CFC and differences in PCREB protein levels between groups. Significance levels for all tests were set at $p<$ 0.05 . There were no significant differences between lenti-GFPcontrols and surgical shams on any of the behavioral measures or Western blotting results, so these rats were pooled into one group for all of the analyses.

\section{Results}

Because of the established function of PP1 in memory formation and CREB-mediated neuronal gene expression (Bito et al., 1996; Genoux et al., 2002) and our recent finding that I-2 is an endogenous PP1 regulator in neurons (Hou et al., 2013), we set out to study the potential role of I-2 in the memory process. We made I-2 KO mice using an I-2 gene-trapping ES cells (Fig. $1 A, B$ ). I-2 global KO mice died as embryos around embryonic day 13.5 (data not shown), but I-2 heterozygous mice were healthy, viable, and fertile and exhibited no obvious phenotypes. Western blotting experiments verified that the I-2 protein was completely absent in I-2 homozygotes, whereas the I-2 protein level was approximately half of that in I-2 wild-type littermates (Fig. 1C). We tested directly whether I-2 plays a critical role in memory formation, first by determining memory retention in $\mathrm{I}-2^{+/-}$mice using a novel object recognition test. $\mathrm{I}-2^{+/-}$mice showed increased novel object recognition 24 and $48 \mathrm{~h}$ after training relative to their wild-type littermates $\left(p<0.05\right.$; the I-2 $2^{+/-}$mice groups tested $1 \mathrm{~min}$ or $1 \mathrm{~h}$ after training showed an increased trend in preference for the novel object, however, this was not significant; Fig. $1 D)$. In a CFC test, $\mathrm{I}-2^{+/-}$mice also showed increased freezing when put into the same chamber $24 \mathrm{~h}$ after conditioning (Fig. $1 E$ ). The observation that $\mathrm{I}-2^{+/-}$mice show increased memory retention was not due to other factors such as altered motor activity because there were no significant differences between these I- $2^{+/-}$mice and their wild-type littermates in open-field tests (data not shown). To complement the mouse KO studies, the interpretation of which could be compounded by potential unknown developmental compensation, and to further analyze in which brain regions I-2 might regulate memory formation, we performed behavioral studies in rats injected 
A

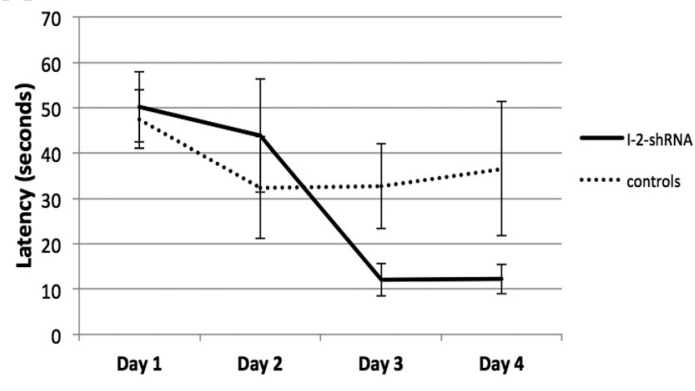

B

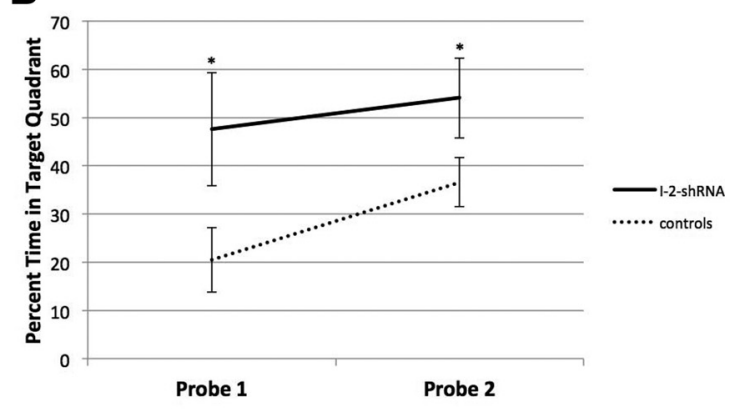

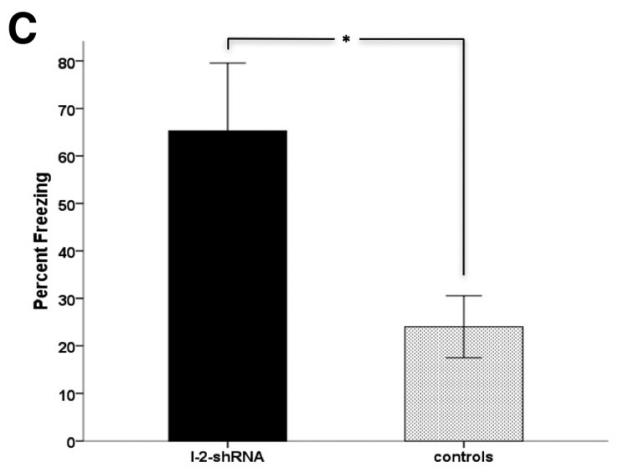

Figure 2. I-2 negatively regulates hippocampus-dependent memory formation in rats. $\boldsymbol{A}$, Rats infused with lenti-I-2-shRNA demonstrated learning during place training ( $p=0.004)$, whereas controls did not $(p=0.642)$. $B$, Rats infused with lenti-l-2-shRNA spent significantly more time in the target quadrant containing the hidden platform than controls during the two probes, which were at the end of days 2 and $4(p=0.02)$. C, Rats infused with lenti-I-2-shRNA demonstrated significantly more freezing than controls in a CFC test; $p=0.03$; lenti-I-2-shRNA $=5$, control $=$ surgical shams (2) + lenti-GFP (3).

with I-2 KD viruses, which we previously reported to be specific and not to have any off-target effect (Hou et al., 2013).

Two weeks after infusion of lenti-I-2-shRNA in the dorsal hippocampus, rats began $4 \mathrm{~d}$ of place training in the water maze. For latency to find the hidden platform across days, a repeatedmeasures ANOVA revealed a significant effect of day $\left(F_{(1,8)}=\right.$ 4.397, $p=0.013)$, no significant effect of group $\left(F_{(1,8)}=0.827\right.$, $p=0.390)$, and no day $\times$ group interaction $\left(F_{(1,8)}=4.615, p=\right.$ 0.116 ) (Fig. 2A). With further analysis of the significant effect of day, we found that lenti-I-2-shRNA demonstrated learning during acquisition of the place task $\left(F_{(1,4)}=7.704, p=0.004\right)$, whereas controls did not $\left(F_{(1,4)}=0.576, p=0.642\right)$. For the probe analysis, which is a measure of learned spatial bias, repeated-measures ANOVA revealed no significant effect of day $\left(F_{(1,8)}=1.268, p=0.301\right)$, a significant effect of group $\left(F_{(1,8)}=\right.$ $9.064, p=0.020)$, and no day $\times$ group interaction $\left(F_{(1,8)}=0.243\right.$, $p=0.637$ ), for percentage of time in the target quadrant (Fig. $2 B$ ). Therefore, rats infused with lenti-I-2-shRNA spent significantly more time in the target quadrant and had a greater spatial bias for the location of the platform than controls.

After place training, rats were given one session of CFC and were tested for fear memory $24 \mathrm{~h}$ later. ANOVA revealed a significant effect of group $\left(F_{(1,8)}=6.989, p=0.030\right)$ in percentage freezing (Fig. 2C) during the first 2 min of testing. These behavioral data support the role of I-2 as a negative regulator of memory formation.

Genoux et al. (2002) has reported that transgenic mice in which PP1 is inhibited show increased memory formation in novel object recognition. Our data indicate that I-2 and PP1 function in the same direction in memory formation, consistent with I-2 acting as a positive regulator of PP1 memory function in vivo. This conclusion is consistent with our previous studies of increased PP1 activity and blocked chemLTD in I-2 KD neurons
(Hou et al., 2013). Because it is known that PP1 is a CREB phosphatase (Bito et al., 1996; Mauna et al., 2011), we next determined whether I-2 can regulate pCREB levels in neurons. We found that pCREB was significantly increased (Fig. $3 A, B$ ) in both brain and cultured neurons in which I-2 was downregulated, suggesting that I-2 is an endogenous pCREB regulator. Consistent with increased pCREB in I-2 KD neurons, we found that I-2 regulated CREB-mediated gene expression because the mRNA expressions of the CREB-regulated genes BDNF, c-fos, Egr1, and Homer-1a were all increased in I-2 KD neurons as measured by qRT-PCR (Fig. 3C). In addition, in the rat lentiviral injection experiments, Western blotting performed on dorsal hippocampus tissue homogenates from individual rats revealed a significant increase in pCREB protein levels in lenti-I-2-shRNA-infused rats compared with controls $\left(F_{(1,7)}=10.509, p=0.014\right)$. Together, the results demonstrate that downregulation of I-2 increases phosphorylation of CREB and support the role of I- 2 as a negative regulator of CREB activity. PP1 is a negative regulator of CREB phosphorylation at Ser 133 and also of memory formation, so our data suggest that I-2 positively regulates these PP1 functions. Consistent with our previous report that I-2 KD led to increased PP1 inhibitory phosphorylation at Thr320 (T320) (Hou et al., 2013), we found that PP1 inhibitory phosphorylation at T320 was also increased in $\mathrm{I}-2^{-1-}$ embryos (Fig. $4 A$ ). Moreover, we found that there was significantly lower PP1 activity in the brain lysates from I-2 het mice compared with those from their WT littermates (Fig. 4B). Furthermore, we measured PP1 enzymatic activity in I-2 immunoprecipitates from cultured neurons. Consistent with the results that show that I-2 may positively influence PP1 activity toward phospho-CREB, we found robust and significant PP1 activity in the I-2-PP1 complex that was comparable to that in a PP1 immunoprecipitate (Fig. 4C). 

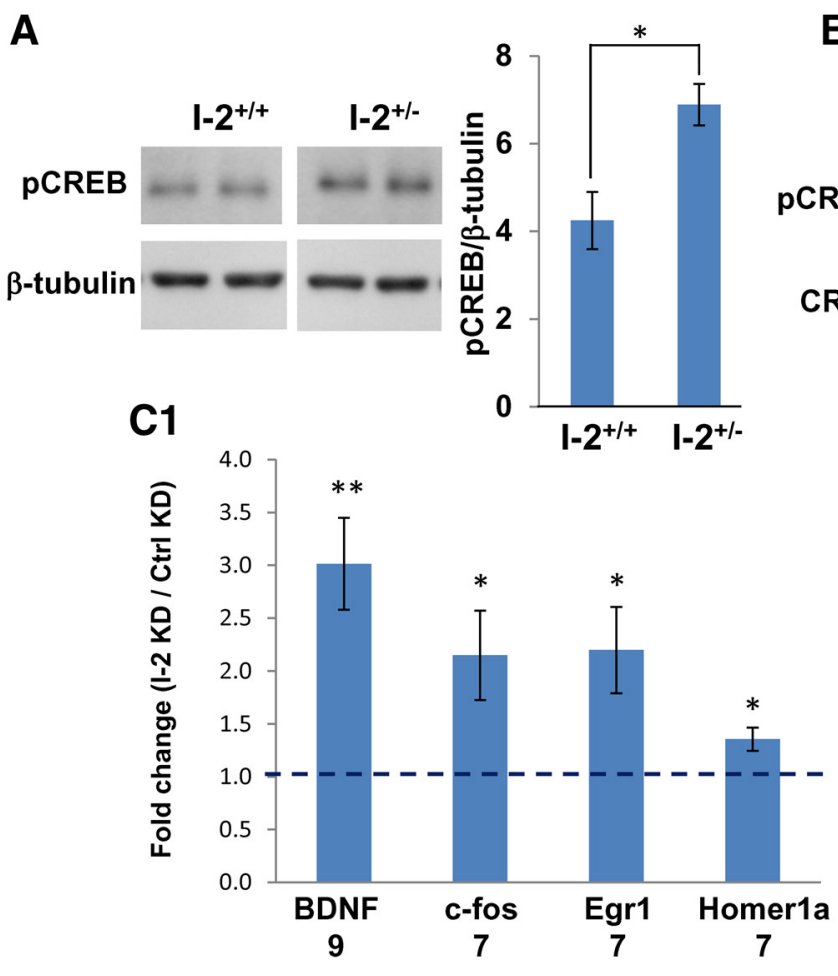

B
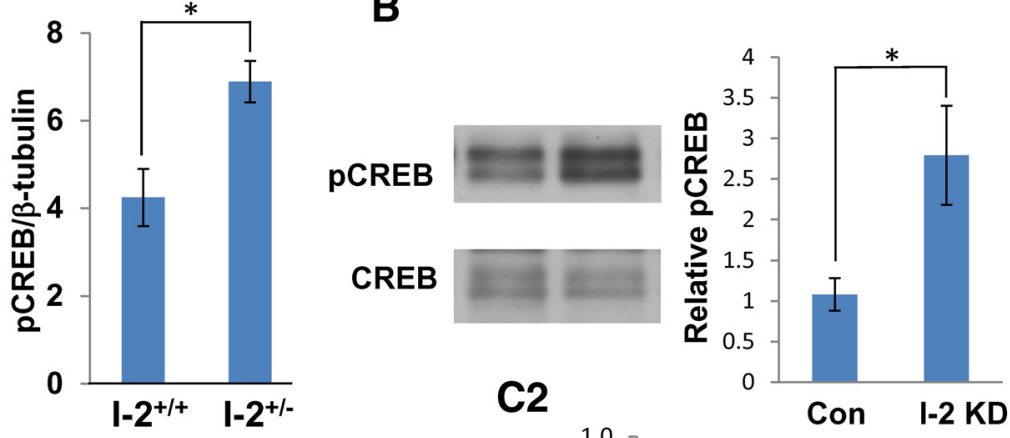

C2

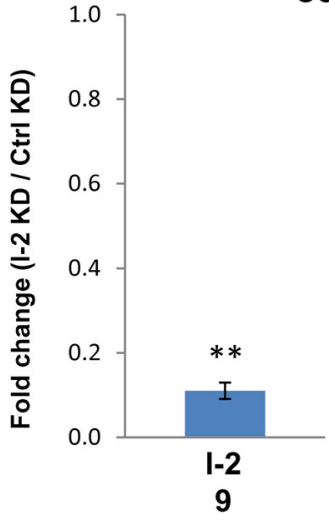

Figure 3. I-2 regulation of CREB-dependent gene expression. $A$, Increase of $p$ CREB in the brains of $\mathrm{l}-2$ heterozygous mice ( 2.5 months old, $n=5$ for each group, $p<0.05,2$-tailed $t$ test). $B, \mathrm{I}-2$ KD leads to increased $p C R E B$ in cortical neurons (21 $\mathrm{d}$ in vitro, $n=3$ for each group, $p<0.05, t$ test). C1, I-2 KD leads to increased expression of BDNF, c-fos, Egr1, and Homer1a genes. C2, qRT-PCR demonstration of successful I-2 knock-down. ${ }^{*} p<0.05,{ }^{* *} p<0.01$, 2-tailed $t$ test.

\section{Discussion}

The regulation of PP1 by I-2 has been well studied biochemically in vitro, including elucidation of a crystal structure of an I-2:PP1 complex (Hurley et al., 2007). However, I-2's in vivo function is still not known. Here, we found the following: (1) that I-2 acts as a memory suppressor through the use of a new I-2 transgenic mouse model that we generated; (2) that localized gene silencing of I-2 in the dorsal hippocampus enhances memory for various hippocampus-dependent tasks in rats; (3) that I-2 is a novel endogenous regulator of CREB activation and subsequently of CREBmediated gene expression, suggesting an underlying signaling pathway for I-2's function in memory formation; and (4) that I- 2 acts as a positive regulator of PP1 function in CREBmediated gene expression and memory formation, contrary to its established in vitro function as a PP1 inhibitor. In this study, we generated novel I-2 KO mice. Even though $\mathrm{I}-2^{-1-}$ mice die as embryos, the I-2 heterozygous mice $\left(\mathrm{I}-2^{+/-}\right)$show increased memory formation in novel object recognition and CFC tests. This is further corroborated by an independent complementary approach: knock-down studies with expression of I-2-shRNA, which has been shown by us previously to be specific and not to have an offtarget effect (Hou et al., 2013). Rats injected with I-2 shRNA-encoding lentivirus into the dorsal hippocampus spent significantly more
A

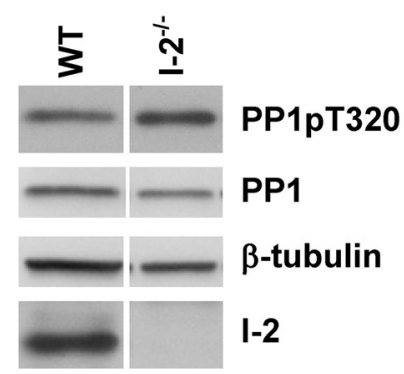

B

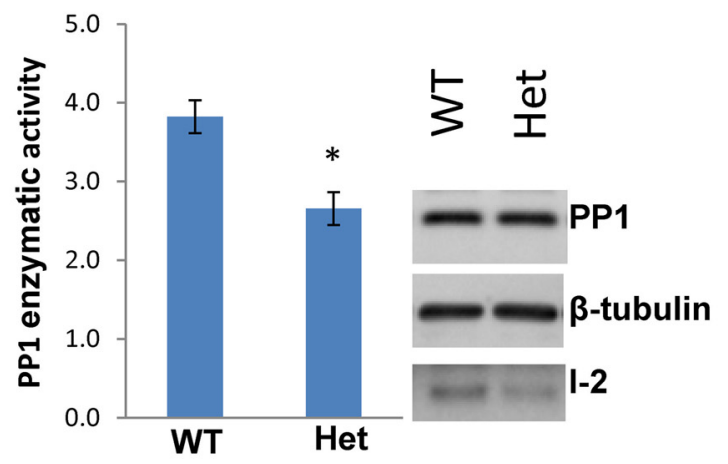

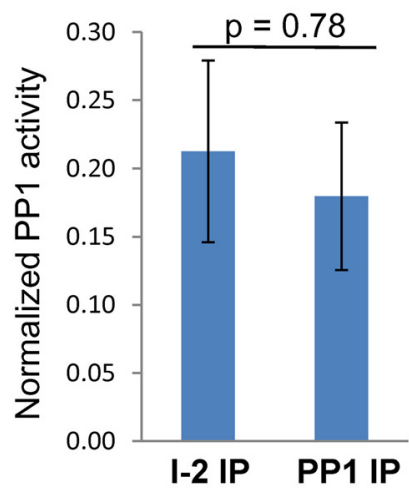

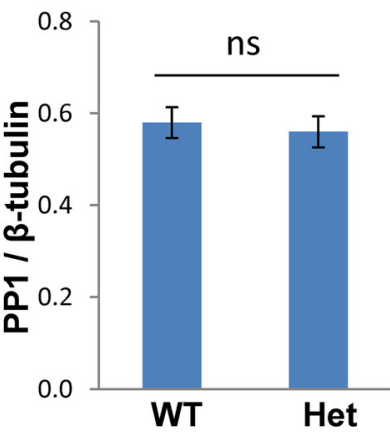

Figure 4. Characterization of $\mathrm{I}-2$ regulation of PP1. $A, \mathrm{PP} 1$ inhibitory phosphorylation at $\mathrm{T} 320$ is significantly increased in $\mathrm{I}-2$ homozygous mice ( $n=3$ for WT, $n=2$ for $1-2$ homozygous mice, PP1pT320/PP1 $=3.5$ that of WT; $t$ test, $p<0.01)$. B, Decreased PP1 activity in 3-month-old I-2 heterozygote mouse brains $(n=5)$ relative to their WT littermates $(n=6)(t$ test: $p<0.01)$. Middle and right, No change in PP1 level in I-2 heterozygous mice brain (tissues are from same set of mice brains used in PP1 activity assay). C, Comparable PP1 activity is observed in I-2 or PP1 immunoprecipitates obtained from $\sim 4$-week-old primary cortical neurons ( $n=4$ for each IP pair, $p=0.78$.). ns, Not significant. 
time in the target quadrant and had a greater spatial bias for the location of the platform than controls in the Morris water maze test. The same group of rats also showed increased freezing in a CFC test relative to control rats. These results definitively demonstrated that I- 2 is a memory repressor. Our studies also revealed that downregulation of I-2, with a recombinant lentivirus expressing I-2 ShRNA, leads to significantly increased CREB phosphorylation at Ser 133 in both primary neurons and in the rat dorsal hippocampus. Further, the qRT-PCR results indicate that I-2 negatively regulated CREB-mediated neuronal gene expression. Our results thus show that knocking down I-2 sustains CREB phosphorylation in the hippocampus and enhances hippocampusdependent memory formation.

When PP1 activity is inhibited in transgenic mice, memory formation in a novel object recognition test is enhanced (Genoux et al., 2002). This constraint function of PP1 on memory formation takes place, most likely, via inactivating CREB-mediated gene expression and is consistent with our previous report that sustained CREB phosphorylation is necessary for memory formation (Colombo et al., 2003). Our findings that knocking down I-2 increases levels of pCREB and CREB target genes support the role of I-2 as a positive regulator of PP1 and explains our behavioral findings. Consistent with the pCREB results, our studies also found that downregulation of I-2 leads to increased PP1 inhibitory phosphorylation at Thr320 in both cultured neurons and mice. The interpretation that I-2 could be a positive regulator of PP1 function in memory formation echoes yeast genetic studies suggesting that an I-2 homolog in yeast may be a PP1 activator in vivo (Tung et al., 1995; Nigavekar et al., 2002).

Studies with recombinant PP1 purified from bacteria has suggested that I-2 might function as a "chaperone" to help fold PP1 and limit its promiscuous serine/threonine and tyrosine phosphatase activities (Alessi et al., 1993). However, our results indicate that PP1 activity is reduced after a reduction in I-2 expression, likely as a result of increased pT320 phosphorylation. Moreover, our studies indicate that KO or knock-down of I-2 has no effect on the level of expression of PP1, which is inconsistent with a general chaperone function for I-2.

PP1 plays critical roles in many physiological processes and pharmacological PP1 inhibitors will thus affect all PP1-related functions. However, different PP1 regulatory proteins $(>100)$ are believed to determine PP1 function in different physiological processes (Heroes et al., 2013). Developing specific inhibitors for PP1 regulatory subunits can thus offer the possibility of specificity in therapeutic intervention of specific PP1 signaling pathways such as salubrinal for GADD34-regulated PP1 function in ER stress (Moreno et al., 2012). Identification of I-2 as a memory suppressor thus provides a novel therapeutic target for treating memory-related diseases in which PP1 signaling may be affected.

\section{References}

Alberts AS, Montminy M, Shenolikar S, Feramisco JR (1994) Expression of a peptide inhibitor of protein phosphatase 1 increases phosphorylation and activity of CREB in NIH 3T3 fibroblasts. Mol Cell Biol 14:4398 - 4407. CrossRef Medline

Alessi DR, Street AJ, Cohen P, Cohen PT (1993) Inhibitor-2 functions like a chaperone to fold three expressed isoforms of mammalian protein phosphatase-1 into a conformation with the specificity and regulatory properties of the native enzyme. Eur J Biochem 213:1055-1066. CrossRef Medline

Barco A, Alarcon JM, Kandel ER (2002) Expression of constitutively active CREB protein facilitates the late phase of long-term potentiation by enhancing synaptic capture. Cell 108:689-703. CrossRef Medline

Bito H, Deisseroth K, Tsien RW (1996) CREB phosphorylation and dephosphorylation: a $\mathrm{Ca}(2+)$ - and stimulus duration-dependent switch for hippocampal gene expression. Cell 87:1203-1214. CrossRef Medline
Cohen P (1989) The structure and regulation of protein phosphatases. Annu Rev Biochem 58:453-508. CrossRef Medline

Colombo PJ, Brightwell JJ, Countryman RA (2003) Cognitive strategyspecific increases in phosphorylated cAMP response element-binding protein and c-Fos in the hippocampus and dorsal striatum. J Neurosci 23:3547-3554. Medline

Genoux D, Haditsch U, Knobloch M, Michalon A, Storm D, Mansuy IM (2002) Protein phosphatase 1 is a molecular constraint on learning and memory. Nature 418:970-975. CrossRef Medline

Heroes E, Lesage B, Görnemann J, Beullens M, Van Meervelt L, Bollen M (2013) The PP1 binding code: a molecular-lego strategy that governs specificity. Febs J 280:584-595. CrossRef Medline

Hou H, Sun L, Siddoway BA, Petralia RS, Yang H, Gu H, Nairn AC, Xia H (2013) Synaptic NMDA receptor stimulation activates PP1 by inhibiting its phosphorylation by Cdk5. J Cell Biol 203:521-535. CrossRef Medline

Hou H, Chávez AE, Wang CC, Yang H, Gu H, Siddoway BA, Hall BJ, Castillo PE, Xia H (2014) The Rac1 inhibitor NSC23766 suppresses CREB signaling by targeting NMDA receptor function. J Neurosci 34:1400614012. CrossRef Medline

Hurley TD, Yang J, Zhang L, Goodwin KD, Zou Q, Cortese M, Dunker AK, DePaoliRoach AA (2007) Structural basis for regulation of protein phosphatase 1 by inhibitor-2. J Biol Chem 282:28874-28883. CrossRef Medline

Impey S, McCorkle SR, Cha-Molstad H, Dwyer JM, Yochum GS, Boss JM, McWeeney S, Dunn JJ, Mandel G, Goodman RH (2004) Defining the CREB regulon: a genome-wide analysis of transcription factor regulatory regions. Cell 119:1041-1054. Medline

Kathirvelu B, Colombo PJ (2013) Effects of lentivirus-mediated CREB expression in the dorsolateral striatum: memory enhancement and evidence for competitive and cooperative interactions with the hippocampus. Hippocampus 23:1066-1074. CrossRef Medline

Kathirvelu B, East BS, Hill AR, Smith CA, Colombo PJ (2013) Lentivirusmediated chronic expression of dominant-negative CREB in the dorsal hippocampus impairs memory for place learning and contextual fear conditioning. Neurobiol Learn Mem 99:10-16. Medline

Le AV, Tavalin SJ, Dodge-Kafka KL (2011) Identification of AKAP79 as a protein phosphatase 1 catalytic binding protein. Biochemistry 50:5279_ 5291. CrossRef Medline

Lonze BE, Ginty DD (2002) Function and regulation of CREB family transcription factors in the nervous system. Neuron 35:605-623. CrossRef Medline

Mauna JC, Miyamae T, Pulli B, Thiels E (2011) Protein phosphatases 1 and $2 \mathrm{~A}$ are both required for long-term depression and associated dephosphorylation of cAMP response element binding protein in hippocampal area CA1 in vivo. Hippocampus 21:1093-1104. CrossRef Medline

Moreno JA, Radford H, Peretti D, Steinert JR, Verity N, Martin MG, Halliday M, Morgan J, Dinsdale D, Ortori CA, Barrett DA, Tsaytler P, Bertolotti A, Willis AE, Bushell M, Mallucci GR (2012) Sustained translational repression by eIF2alpha-P mediates prion neurodegeneration. Nature 485 : 507-511. Medline

Nigavekar SS, Tan YS, Cannon JF (2002) Glc8 is a glucose-repressible activator of Glc7 protein phosphatase-1. Arch Biochem Biophys 404:71-79. CrossRef Medline

Sakagami H, Kondo H (1995) Molecular cloning of the cDNA for rat phosphatase inhibitor- 2 and its wide gene expression in the central nervous system. J Chem Neuroanat 8:259-266. CrossRef Medline

Shaywitz AJ, Greenberg ME (1999) CREB: a stimulus-induced transcription factor activated by a diverse array of extracellular signals. Annu Rev Biochem 68:821-861. CrossRef Medline

Siddoway BA, Altimimi HF, Hou H, Petralia RS, Xu B, Stellwagen D, Xia H (2013) An essential role for inhibitor-2 regulation of protein phosphatase-1 in synaptic scaling. J Neurosci 33:11206-11211. CrossRef Medline

Siddoway B, Hou H, Yang J, Sun L, Yang H, Wang GY, Xia H (2014) Potassium channel Kv2.1 is regulated through protein phosphatase-1 in response to increases in synaptic activity. Neurosci Lett 583:142-147. CrossRef Medline

Tang YP, Shimizu E, Dube GR, Rampon C, Kerchner GA, Zhuo M, Liu G, Tsien JZ (1999) Genetic enhancement of learning and memory in mice. Nature 401:63-69. CrossRef Medline

Tung HY, Wang W, Chan CS (1995) Regulation of chromosome segregation by Glc8p, a structural homolog of mammalian inhibitor 2 that functions as both an activator and an inhibitor of yeast protein phosphatase 1 . Mol Cell Biol 15:6064-6074. CrossRef Medline 